\title{
PERTIMBANGAN PENERAPAN TEKNOLOGI TEPAT GUNA DALAM PERENCANAAN MIHRAB MASJID DARUL IHSAN PONDOK PEKAYON INDAH BEKASI SELATAN
}

\author{
Diah Anggraini ${ }^{1}$, Samsu Hendra Siwi ${ }^{2}$, Meike Choandi ${ }^{3}$ dan Joni Chin ${ }^{4}$ \\ ${ }^{1}$ Jurusan Teknik Arsitektur, Universitas Tarumanagara Jakarta \\ Email: diah_ismono@yahoo.com \\ ${ }^{2}{ }^{1}$ Jurusan Teknik Arsitektur, Universitas Tarumanagara Jakarta \\ Email:sh.siwi@gmail.com \\ ${ }^{3}$ Jurusan Teknik Arsitektur, Universitas Tarumanagara Jakarta \\ Email: mieke_choandi@hotmail.com \\ ${ }^{4}$ Jurusan Teknik Arsitektur, Universitas Tarumanagara Jakarta \\ Email: jonichin77@gmail.com
}

\begin{abstract}
ABSTRAK
Mihrab masjid merupakan tempat imam memimpin shalat. Mihrab terletak tepat di tengah-depan ruang masjid. Beberapa pertimbangan desain Mihrab dilakukan berdasarkan hukum Islam dan teori tentang kenyamanan audio visual. Pemakaian LCD dan sound system sebagai salah satu solusi teknologi tepat guna demi tercapainya kebutuhan kenyamanan audio-visual ini. Namum, desain, perletakan serta biaya menjadi sangat penting sebagai dasar pertimbangan terwujudnya mihrab yang diinginkan. Kegiatan PKM Jurusan Arsitektur Untar di Masjid Darul Ihsan, Pekayon Jaya, Bekasi dilakukan secara berkelanjutan. Kali ini, PKM berupa desain mihrab dengan pertimbangan estetika dan fungsional (berdasarkan perhitungan teori audio visual). Sebuah tantangan desain yaitu desain dengan eksisting, hukum Islam dan fungsional secara audio visual. Perletakan LCD dan layar yang menyatu dengan mihrab merupakan tantangan desain tersendiri sehingga desain mihrab dan desain perletakan LCD dan layar memenuhi kebutuhan secara fungsional dan estetika. Metoda yang dilakukan adalah melakukan pengamatan, pengukuran dan wawancara pada pengurus, kemudian melaksanakan proses desain serta feedback pada pengurus sekaligus sebagai pemakai, kemudian merevisi desain sesuai dengan feedback tersebut. Tujuan dari desain mihrab diharapkan dapat meningkatkan kualitas ibadah. Desain mihrab yang dilakukan oleh Tim PKM ini diharapkan bisa sebagai pedoman dalam pembangunan mihrab masjid.
\end{abstract}

Kata kunci: mihrab; masjid; perancangan.

\section{PENDAHULUAN}

Kondisi Masjid Darul Ihsan saat ini telah selesai 90\%. Masjid Darul Ihsan berlokasi di Jalan Ketapang, Pondok Pekayon Indah Bekasi Selatan (Gambar 1). Lokasi masjid ini di pojok dengan "eye catching" dengan mudah dikenali oleh masyarakat yang melintasinya. Masijd ini sebagai masjid lingkungan dengan kapasitas jamaah sekitar 400 orang. Sambil terus melanjutkan penyelesaian pembangunan fisiknya, Masjid ini telah difungsikan secara penuh. Kegiatan rutin seperti sholat berjamaah lima waktu dan sholat Jumat telah berlangsung dan diikuti jamaah yang relatif cukup banyak. Selain untuk kegiatan peribadatan, masjid ini juga memiliki dan menyelenggarakan pelayanan bagi masyarakat sekitar dalam bentuk penyediaan fasilitas: TPA (Taman Pendidikan Al Quran), Perpustakaan, Majelis Taklim, dan sebagainya. Untuk kegiatan ibadah sholat berjamaah, fasilitas mihrab bagi Imam yang memimpin sholat saat ini belum ditangani dengan baik. Posisi mihrab di masjid ini seperti pada Gambar 2 dan kondisi mihrab saat ini masih berupa ruang/ceruk pada dinding tanpa ornamen dekoratif sebagaimana umumnya mihrab masjid (Gambar 3). Mihrab menjadi point of interest yang memperkuat orientasi jamaah terhadap arah kiblat. 


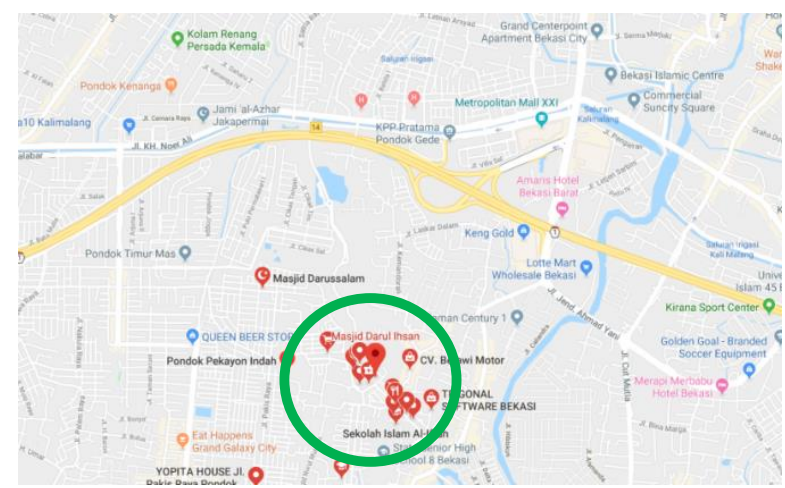

Gambar 1. Lokasi Masjid Darul Ihsan di Pondok Pekayon Indah, Bekasi Selatan (Sumber: Google Map)

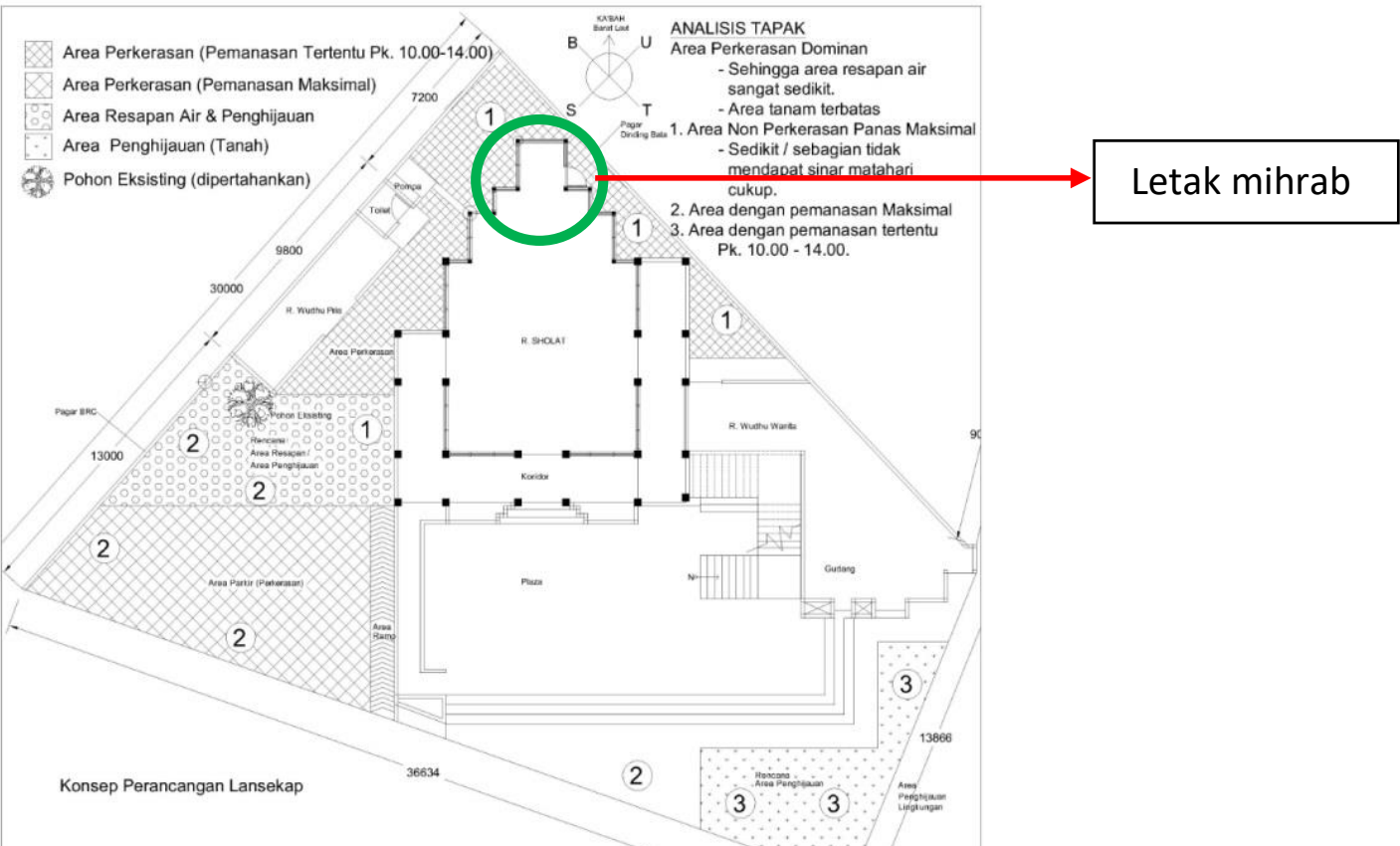

Gambar 2. Posisi mihrab terhadap masjid (sebagai tempat imam)
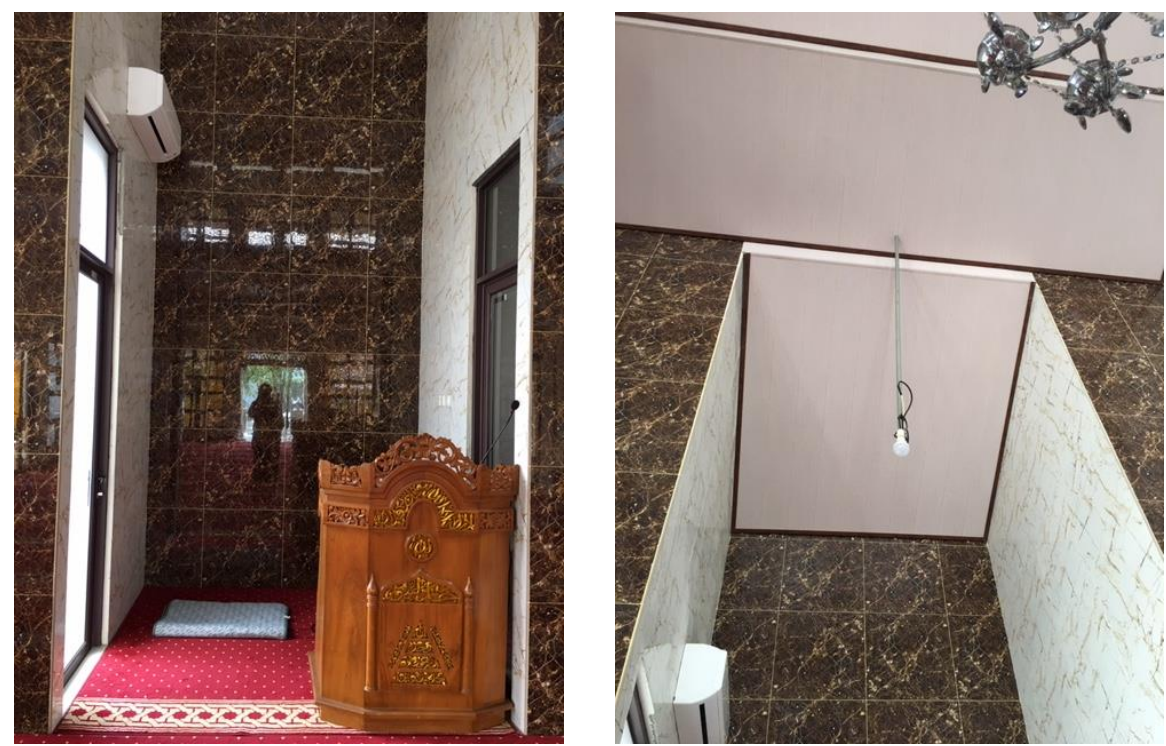

Gambar 3 dan Gambar 4. Kondisi mihrab eksisting 


\section{METODA PELAKSANAAN}

Kegiatan perencanaan dan perancangan mihrab masjid ini didahului dengan riset tentang peran mihrab dalam suatu masjid, prinsip-prinsip perancangan suatu mihrab yang sesuai dengan kaidah syareat Islam, studi tipologi mihrab di dalam dan di luar negeri. Analisis teknis arsitektural dilakukan pada ruang mihrab di masjid Darul Ihsan, meliputi letak, bentuk dan ukuran ruang eksisting yang tersedia, jarak dan sudut pandang khususnya dari arah makmum dan jama'ah ke arah mihrab, sound system dan akustik. Luaran dari kegiatan ini adalah gambar perancangan desain mihrab dengan mempertimbangan kenyamanan visual bagi jamaah dengan posisi duduk (saat mendengarkan kajian dengan melihat layar LCD) dari berbagai posisi duduk di dalam ruang masjid. Sudut pandang dengan memperhitungan teori kenyamanan visual menjadi penting agar mendapatkan desain yang tepat guna.

\section{Konsep Perancangan Mihrab Masjid}

Mihrab (Bahasa arab: محراب) adalah ceruk setengah lingkaran atau tempat kecil yang ada di dinding paling depan masjid atau Musala yang menunjukkan arah kiblat dan merupakan tempat untuk Imam memimpin sholat berjemaah dalam suatu masjid. Kata mihrab juga bisa dimaksudkan tempat mendekatkan diri pada Allah SWT. Arah mihrab juga dipakai sebagai penanda arah masjid ke kiblat (Carey, 2010 pp 22). Karena perannya yang sangat penting, maka mihrab umumnya didesain lebih menonjol dari bagian lain di suatu masjid. Sebagai tempat Imam memimpin sholat, mihrab biasanya berukuran kecil sekitar $2 \times 2$ meter sampai $2 \times 3$ meter, agar tidak terlalu banyak mengurangi space untuk sholat para Jama'ah. Desain mihrab walaupun menonjol namun tetap harus memberikan keteduhan dan elemen desain estetiknya tidak menyebabkan terganggunya kekhusukan sholat berjama'ah. Selain itu sesuai dengan kaidah seni dalam Islam, suatu mihrab harus menghindari pengkultusan suatu mahluk hidup atau benda selain Allah, yang akhirnya bisa menyebabkan syirik. Antara lain tidak menggunakan bentuk manusia dan hewan dalam elemen dekorasinya ( Jones, 2002 pp. 144). Desain ornamennya harus berkarakter Islami yang umumnya menggunakan pola-pola geometris dan menyajikan seni kaligrafi, yang memuat ayat Al Qur'an (Jones, 2002, pp.159). Mihrab bervariasi dalam ukuran namun yang berbentuk seperti rongga/relung dan didekorasi. Selain itu bentuk ruang mihrab ditujukan untuk memperkeras suara imam selama sholat, yang harus terdengar dengan jelas walaupun tanpa mikrofon. Untuk keperluan penerapan elemen estetik, saat ini telah berkembang berbagai material yang praktis dan mudah pemasangannya. Banyak masjid di Indonesia telah menggunakan elemen desain mihrab dengan menggunakan GRC relief panel maupun GRC kerawangan.

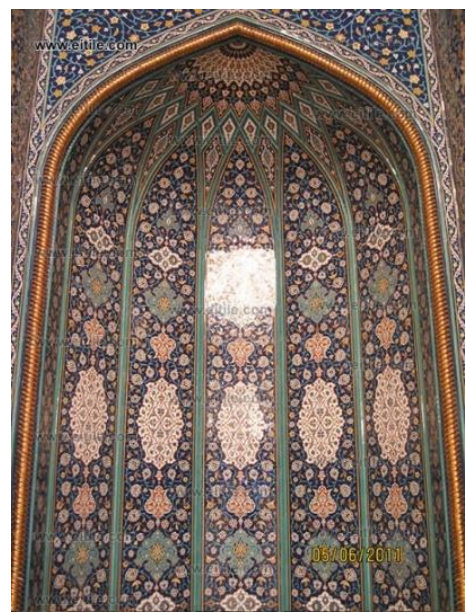

Gambar 5. Mihrab umumnya berupa ceruk pada dinding masjid ke arah kiblat, sekaligus berfungsi untuk mengeraskan suara imam saat memimpin sholat berjamaah 


\section{Kenyamanan Visual Dalam Masjid}

Fungsi masjid sendiri lebih banyak sebagai tempat shalat, namum beberapa kali (dalam program kegiatan jamaah/DKM Masjid) sering mengadakan kajian-kajian atau ceramah. Untuk kebutuhan inilah maka DKM masjid memberikan fasilitas ruang dengan pemenuhan tuntutan kebutuhan audio visual. Kenyamanan visual pada interor masjid sangat diperlukan saat kegiatan kajian/ceramah yang membutuhkan paparan di layar (LCD) yang bisa dilihat oleh jamaah/orang yang hadir di masjid dengan posisi duduk. Hal ini tentu membutuhkan pendekatan teori perhitungan sudut pandang objek seperti yang dilakukan untuk ruang kelas dan cimena, seperti pada Gambar 6 dan Gambar 7.

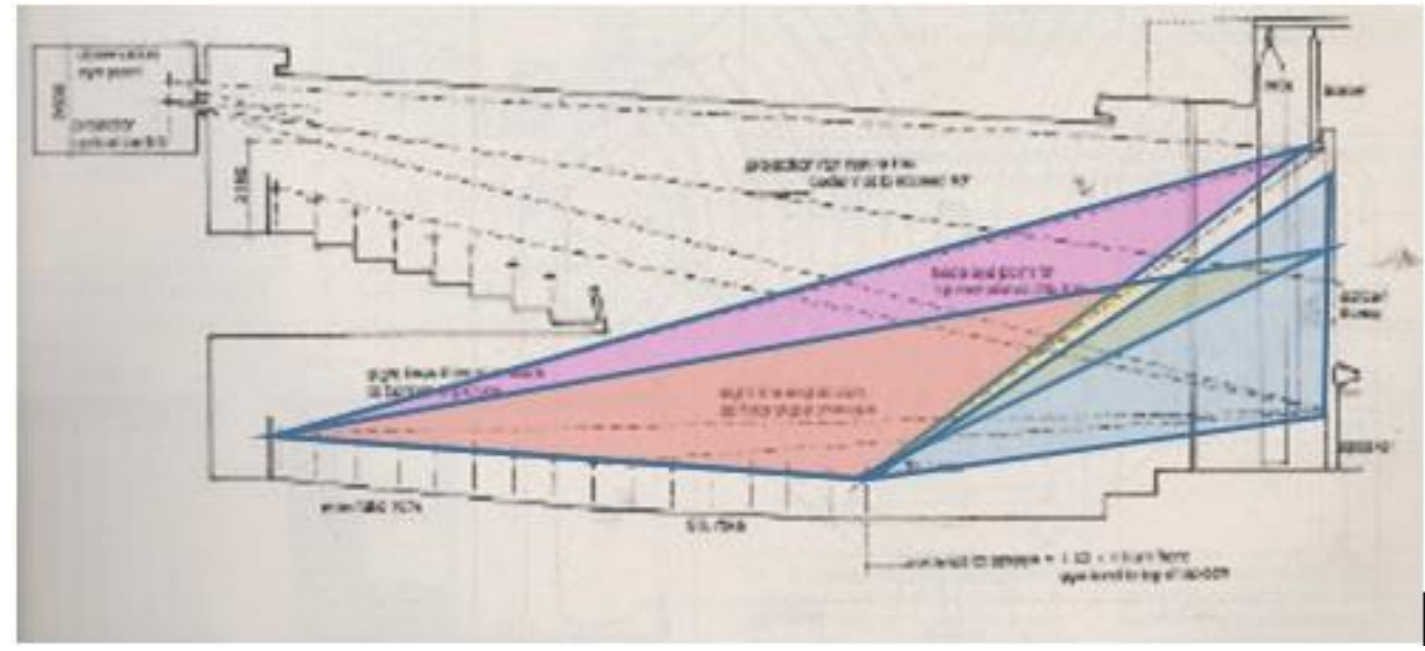

Gambar 6. Pendekatan perhitungan sudut pandang pada cinema secara vertikal (sumber: Neufert Architect'Data, 1980)

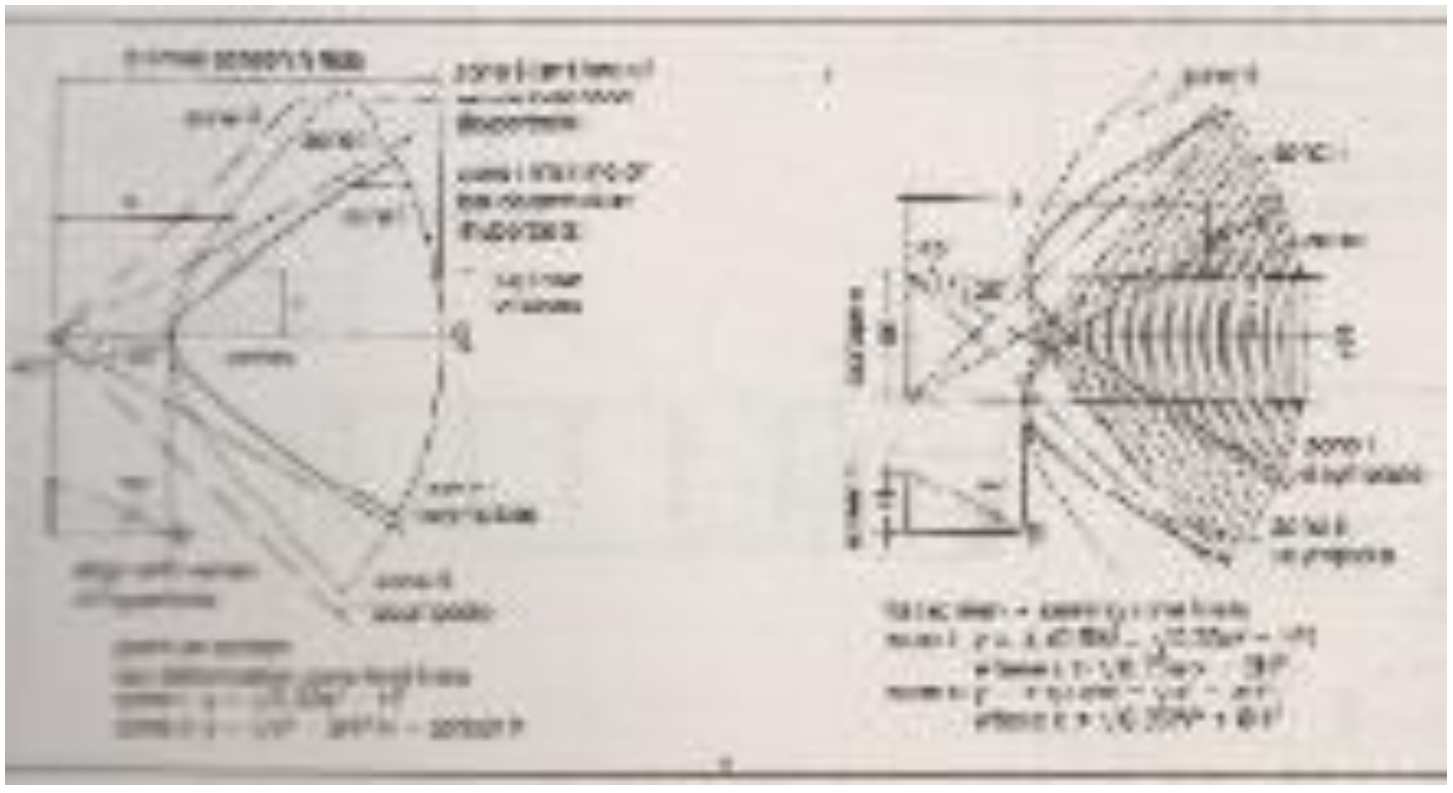

Gambar 7. Pendekatan perhitungan sudut pandang pada cinema secara horisontal (sumber: Neufert Architect'Data, 1980) 


\section{HASIL PENELITIAN}

Ruang utama masjid berbentuk segi empat dengan variasi lekukan-lekukan yang membentuk ceruk pada mihrab. Ruang untuk mihrab telah tersedia, berukuran 2.00 × 2.15 meter. Kemudian secara bergradasi melebar ke arah area sholat.

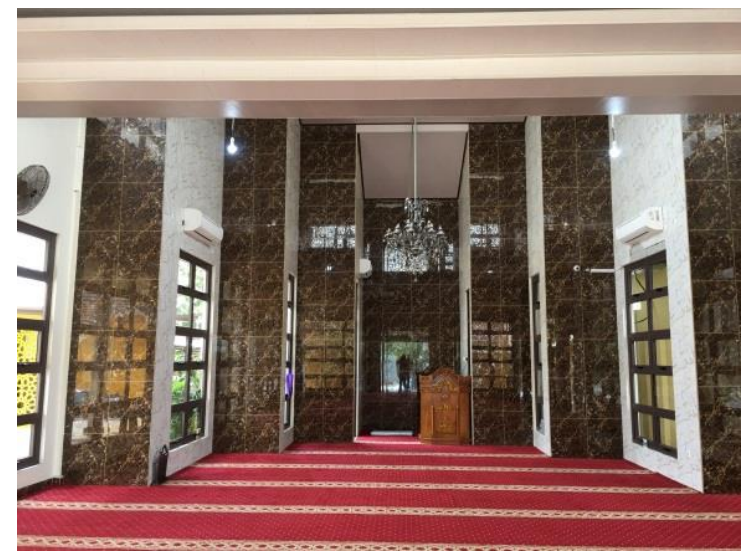

Gambar 8. Ruang utama masjid ke arah mihrab

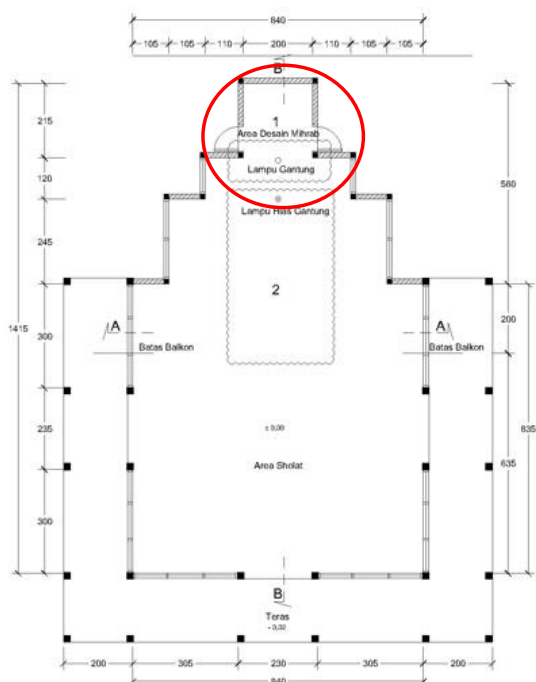

Gambar 9. Denah area sholat, posisi lampu dan area mihrab

Gambar potongan ruang utama masjid menunjukkan bentuk dan ketinggian plafond yang bervariasi. Pada area ceruk mihrab mempunyai plafon miring yang terendah.

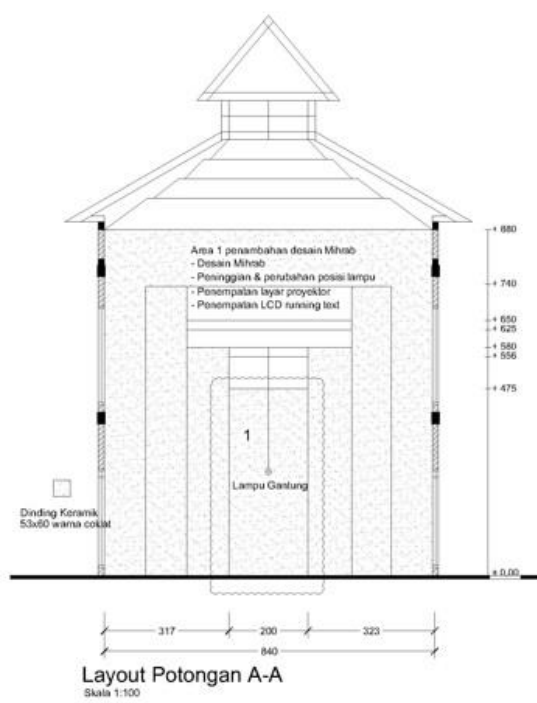

Gambar 10. Potongan ruang sholat ke arah kiblat

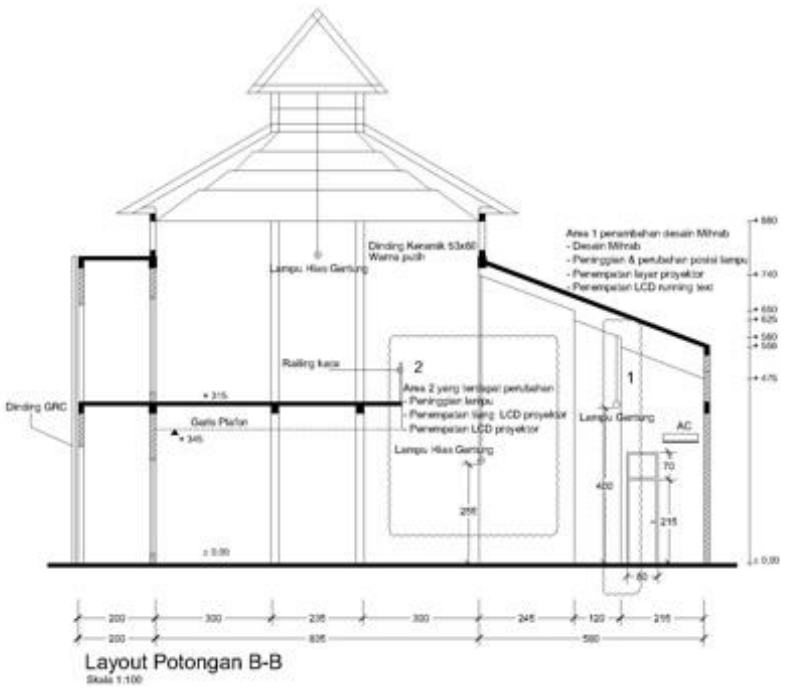

Gambar 11. Potongan memanjang ruang masjid

\section{Analisis Jarak Dan Sudut Pandang Jamaah Ke Arah Mihrab}

Jarak antara mihrab dengan Jama'ah terjauh adalah 12 meter. Ketika sholat berjamaah gerakan sholat Jama'ah mengikuti gerakan Imam, yang dipandu dengan suara takbir, sehingga tidak harus melihat secara langsung. Pada acara kajian, ceramah dan khotbah, kegiatan utama adalah mendengarkan dan tanya jawab yang mengutamakan interaksi dan tatap muka pada aktivitas ini. Selain kehadiran penceramah dan khotib di mimbar, saat ini sudah umum bila disertai dengan 
tayangan yang menggunakan perangkat LCD yang terdiri dari proyektor dan layar tayangan. Sehingga kejelasan dan keleluasaan pandangan Jama'ah ke arah mimbar/penceramah dan ke layar tayangan LCD menjadi penting.

Posisi ideal untuk layar tayangan adalah pada sisi luar ceruk mihrab. Pada sisi ini sudut pandang Jama'ah dinilai paling maksimal. Sedang mimbar tempat khotib dan penceramah diletakkan pada posisi kanan mihrab (lihat Gambar 12 dan Gambar 13) sehingga tidak menghalangi layar tayangan namun tetap dapat terlihat jelas oleh Jemaah.

Situasi saat kajian/ceramah/khotbah, Jama'ah duduk di lantai dan penceramah/khotib berdiri di mimbar. Mengacu pada hasil analisis sudut pandang diusulkan perletakan layar tayangan LCD, running text dan mimbar sebagaimana pada gambar.

Tinggi orang duduk diperkirakan antara $80-100 \mathrm{~cm}$. Sehingga untuk memberikan kemudahan dan kenyamanan pandangan kepada Jemaah yang duduk paling belakang, sisi bawah layar LCD perlu diletakkan minimal pada ketinggian $1.20 \mathrm{~m}$ dari lantai. Sementara sisi paling tinggi dipertimbangkan terhadap ukuran layar. Untuk kenyamanan Jama'ah yang duduk paling depan, sudut vertikal maksimum 30 derajat, sehingga penyesuain sudut pandangnya adalah dengan memberi jarak sekitar 3.60 meter dari layar LCD.
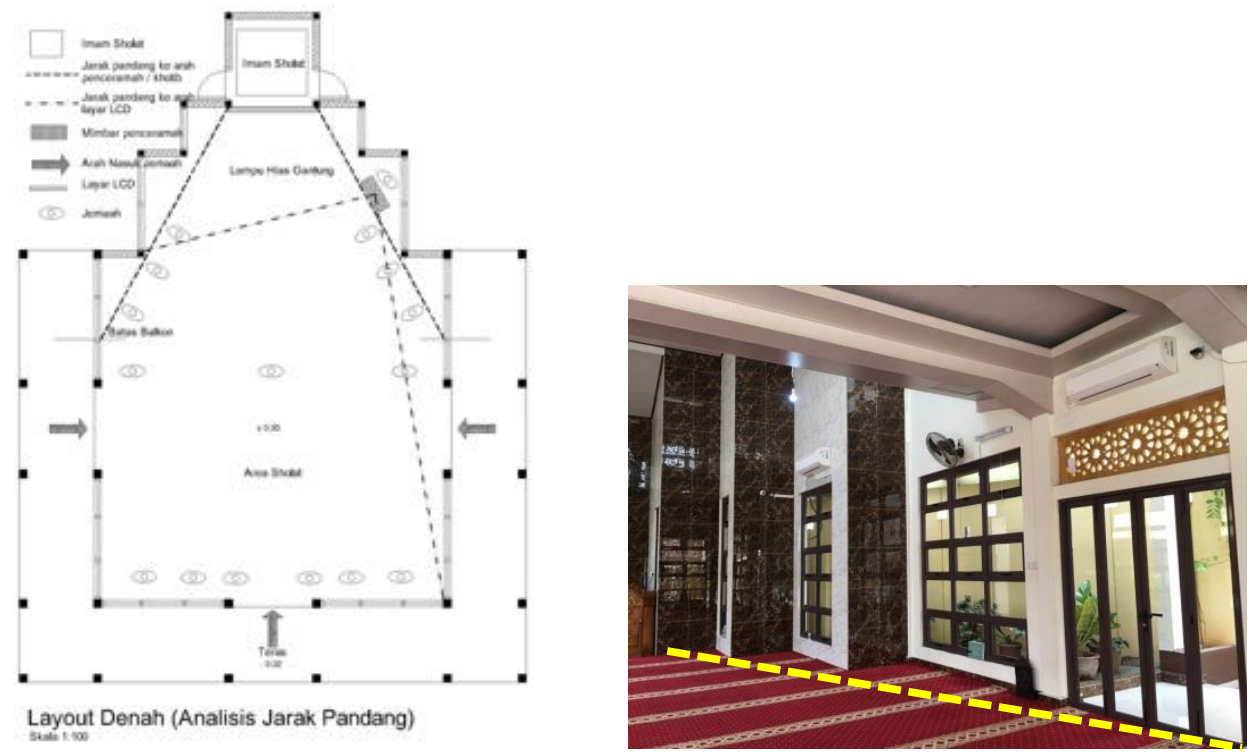

Gambar 12. Analisis jarak pandang

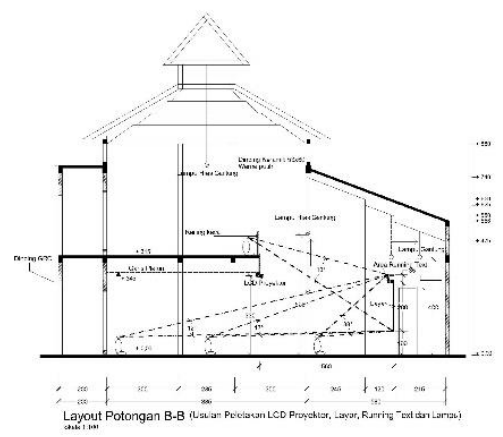

Gambar 13. Potongan memanjang untuk analisis jarak pandang 


\section{Rencana Perletakan Layar Lcd Dan Running Text}

Berdasarkan hasil analisis tentang sudut dan jarak pandang Jemaah ke arah mimbar dan layar tayangan LCD, maka diusulkan seperti pada Gambar 14 dan Gambar 15.

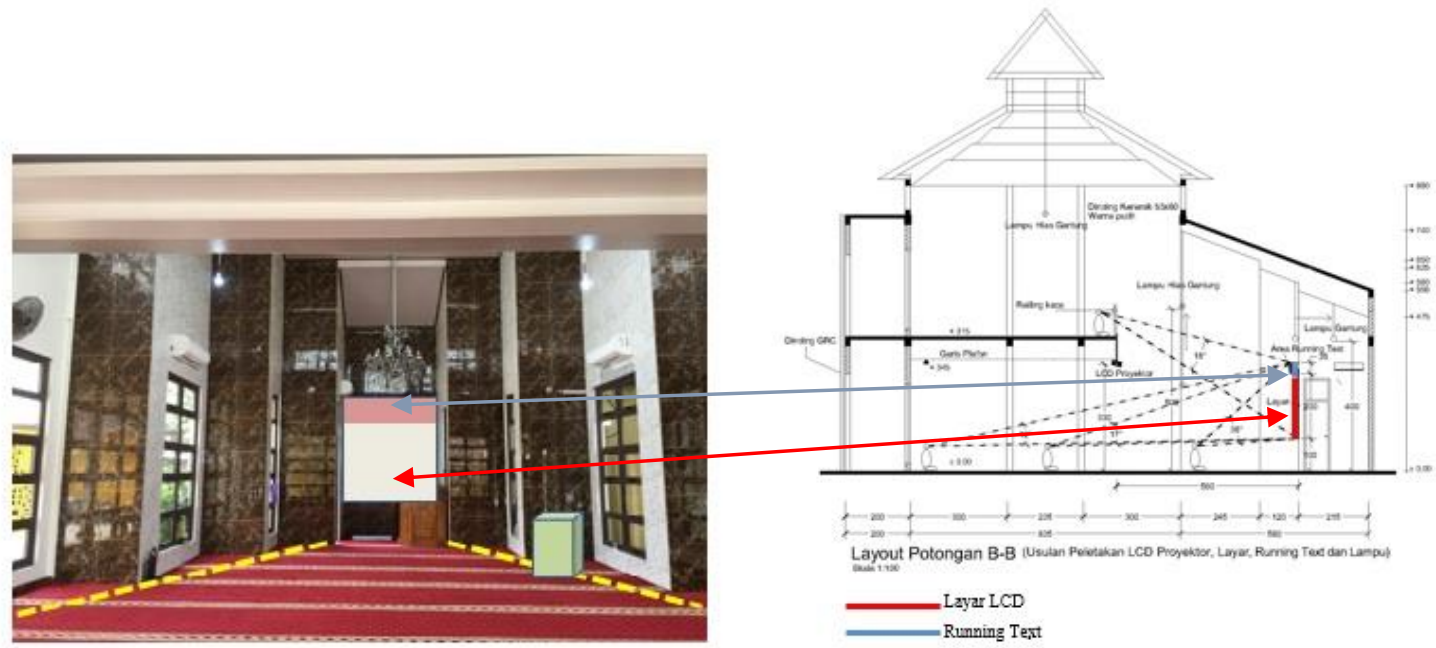

Gambar 14. Rencana perletakan running text dan layar LCD

Gambar 15. Perletakan running text dan layar LCD

Ukuran layar LCD ${ }^{1}$ adalah $\mathrm{Y}=$ jarak audiens/8, dan ukuran panjangxlebar layar minimalnya adalah Y x (1,5Y). Pada masjid Darul Ihsan, Jama'ah yang duduk paling belakang berjarak 12 meter dari layar, sehingga ukuran layarnya minimal adalah 12/8 =1.5 meter. Panjang x lebar layar adalah 1.5 x 2.25 M2. Untuk menghindari gangguan pandangan, diusulkan lampu Kristal dan lampu gantung ditinggikan.

\section{Rancangan/desain Arsitektural Mihrab}

Gambar di bawah ini menunjukkan letak mihrab dan elemen dekoratifnya. Seluruh elemen pembentuk mihrab dibuat tanpa mengubah ruang mihrab eksisting. Melainkan menambahkan struktur baru yang ditempelkan di antara ceruk mihrab eksisting. Struktur tersebut terdiri dari rangka menggunakan besi holo, berfungsi untuk menempelkan elemen dekoratif yang didesain dengan motif-motif geometris dan kaligrafi. Elemen dekoratif tersebut dibuat dari papan kayu setebal $6 \mathrm{~mm}$ yang dilubangi menggunakan teknik lasser cuting, sehingga berkesan transparan/kerawangan. Penggunaan teknik lasser cutting dipilih karena menginginkan hasil yang maksimal dalam menyajikan motif geometris yang berulang dan tulisan kaligrafi yang terkontrol dengan baik. Untuk memberikan kesan yang menarik, kerawangan tersebut dilengkapi dengan pencahayaan dari sisi belakang. Desain ornamen geometris pada mihrab masjid seperti pada Gambar 16.

\footnotetext{
${ }^{1}$ Juni 17, 2013 - indovisualprojector
} 


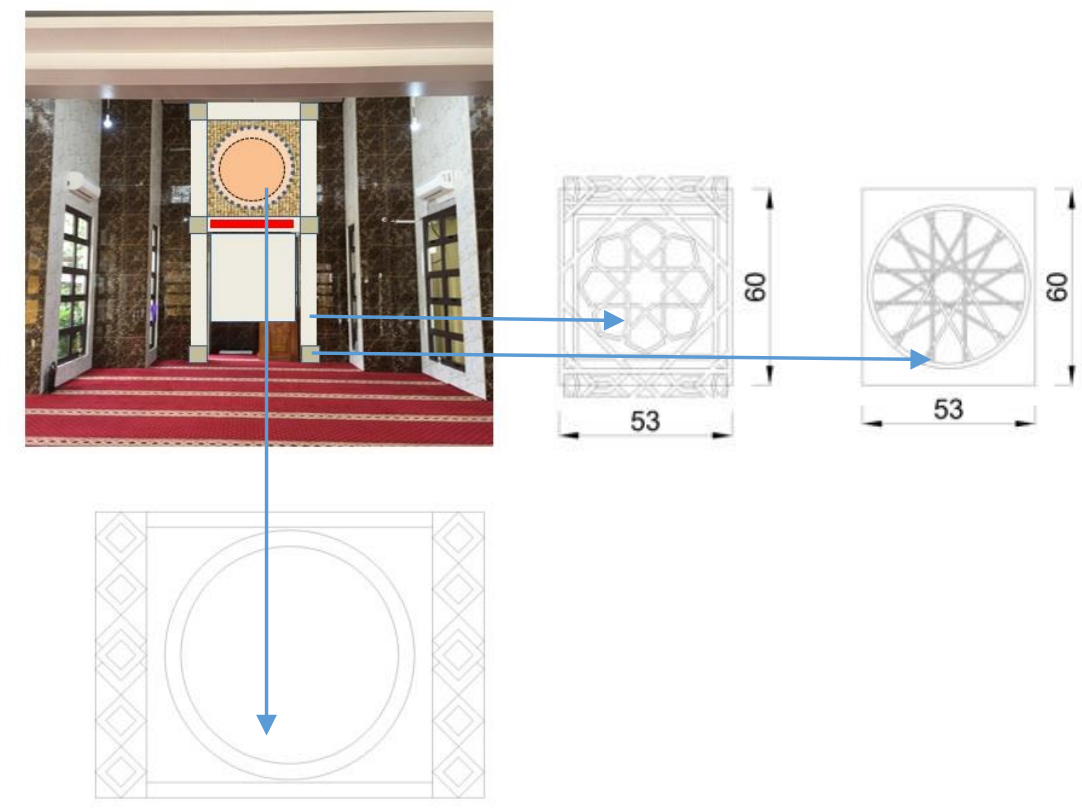

Gambar 16. Ornamen geometris pada mihrab masjid

\section{KESIMPULAN DAN SARAN}

Ruang mihrab telah tersedia sejak awal, yaitu mulai proses perancangan Masjid Darul Ihsan, sehingga perancangan mihrab selanjutnya diupayakan untuk memanfaatkan secara maksimal potensi ini. Meskipun dalam pelaksanaannya, terdapat beberapa keterbatasan yang memerlukan penyesuaian desain arsitektural dan konstruksi. Desain memperhatikan pemilihan material yang banyak tersedia di pasaran dan menggunakan teknik yang mudah diterapkan oleh pelaksana di lapangan, dengan harga terjangkau namun tetap dapat menghasilkan desain yang baik dan sesuai kaidah ke Islaman.

Pelaksanaan pembuatan mihrab disarankan untuk tidak mengganggu kegiatan ibadah dan kegiatan rutin Masjid Darul Ihsan, pelaksana dianjurkan untuk sangat berhati-hati agar penambahan konstruksi untuk mihrab tidak berpotensi merusak material eksisting (misalnya dinding keramik dan karpet, melibatkan tenaga teknisi untuk pemasangan layar LCD, Proyektor LCD dan running text, lampu, sound system dan sebagainya, pengguna baik pengurus masjid maupun Jemaah bersama-sama merawat dan menjaga agar mihrab dapat selalu bersih, indah agar dapat berfungsi dengan maksimal dalam mendukung proses ibadah.

\section{REFERENSI}

Carey, Moya, The Complete Illustrated Guide to Islamic Art and Architecture, Hermes House, London, 2010

Gazalba, Sidi, Mesjid Pusat Ibadah dan Kebudayaan Islam, Pustaka Al Husna, Jakarta, 1995.

Jones, Dalu, Architecture of The Islamic Word, Thames \& Hudson, London, 2002

Kartika Purnomo Edy, Bentuk dan Makna Simbolik Pada Mihrab Masjid Raya Al-Muttaqun Prambanan Klaten, Skripsi UNY, Prodi Pendidikan Seni Rupa, Fakultas Bahasa dan Seni, 2017.

Sabiq, Sayyid, Fikih Sunah 2, Al Ma'arif, Bandung, 1998. 
Nazhar, R.D., Kajian Makna: Mihrab Masjid Kontemporer Al-Irsyad, Kota Baru Parahyangan.

Serat Rupa Journal of Design. September 2016. Vol .1, No 2: 246-257.

Neufert, Ernst, Architect' Data, Granada Publishing, Granada, 1980

Siwi, Samsu Hendra, Aspek Theologis dan Budaya sebagai Pendekatan Konsep Perancangan

"Model" Desain Surau di Padang Pariaman, Prosiding seminar Nasional Arsitektur Islam 3, Malang, 2013.

Shihab, Quraish, Wawasan Al Qur'an, Mizan, Bandung, 1997.

Syamsiyah, N.R., Transformasi Fungsi Mihrab Dalam Arsitektur Masjid, Studi Kasus: Masjidmasjid Jami' di Surakarta. Jurnal Teknik Gelagar, Vol. 18, No. 01, April 2007 